\title{
Flexural, Tensile and Compressibility Behavior of Self Compacting Concrete by using Glass Fibers
}

\author{
Harshitha M N, Nikhil Khatavakar
}

\begin{abstract}
Fiber Reinforced Self Compacting Concrete" (FRSCC) is composed of cement, different sizes of coarse and fine aggregates, which integrate with fiber. In this current investigation, M40 grade Self Compacting Concrete reinforced with glass fibers has been developed using the Nan Su method. Fresh state and hardened state properties of Glass Fiber Reinforced Self Compaction Concrete are studied for glass fibers of different aspect ratio $(875,1285 \& 1714)$ and percentage of volume fraction $(0,0.25,0.5,0.75 \& 1)$. From the investigation carried out it is found that incorporation of glass fibers of aspect ratio 1285 and percentage of volume fraction 0.5 to SCC attains better compressive and flexural strength compared to other mixtures and also incorporation of glass fibers of aspect ratio 1285 and percentage of volume fraction 0.75 to SCC attains better split tensile strength compared to other mixtures.
\end{abstract}

Keywords: Self Compaction Concrete, Glass fibers, Tryout, Aggregates.

\section{INTRODUCTION}

$E_{\text {very year an estimate of 10-12 billion tons of concrete is }}$ consumed in the world. Apart from concrete only water is used by humans in such colossal expanse. Concrete structures longevity is the factor that worried the engineers for many years. Now by vibrating regular concrete we can achieve required compaction that makes the structure of concrete long-lasting. But we have to be sure of not over vibrating the structures because it may segregate. It is difficult to get superior density and invariable material quality in considerable time and effort with regular concrete. Longevity situations occur when steel is not enclosed by concrete appropriately. To get better of these scenarios notion of Self-Compacting Concrete (SCC) is initiated. The most vital material that's been developed in the industry of construction is SCC. To diminish the likelihood danger that may cause by human factor is the sole impetus of SCC development. Due to

Revised Manuscript Received on December 30, 2019.

* Correspondence Author

Harshitha M N, Department of Civil Engineering, JSS Academy of Technical Education, Bengaluru, India.

Email:harshithamn@jssateb.ac.in

Nikhil Khatavakar, Department of Civil Engineering, JSS Academy of Technical Education, Bengaluru, India.

Email:nikhilkhatavakar@gmail.com

(C) The Authors. Published by Blue Eyes Intelligence Engineering and Sciences Publication (BEIESP). This is an open access article under the CC BY-NC-ND license (http://creativecommons.org/licenses/by-nc-nd/4.0/) its fair amount of contrast in properties with regular slump concrete and its fascinating properties it is finding its use all over the world. In this concreting technique the requirement of labor is fewer in contrast to earlier technique and maintenance of equipment. SC technique also reduces the span of construction by resolving the concrete emplacement issue in laboriously reinforced sections. By adding the minerals and chemicals into concrete it is feasible to enhance the mechanical properties.

\section{LITERATURE REVIEW}

HAJIME OKAMURA et.al has studied about longevity of concrete composition. Many analyses attend to consummate suitable assent testing process and coherent process for composition of mix at location has concurrently primarily been admitted for SC concreting. Thus large application of $\mathrm{SC}$ concreting is done by rectifying the headmost hamper for its execution. Inventory construction design and composition methods are run through using SC concreting depiction [2]. TIMO WUSTHOLZ has worked out about the flow ability of SC concreting. In this tryout, J-Ring test which empowers enumeration of bulk concrete blocks [3].

NAN SU et.al has proposed a new mix design method for SCC. Initially, required amount of aggregate and paste of binders used to fill in to the voids of aggregate is to be determined. Various test such as Slump flow, V-funnel, L-flow, U-box and compressive strength tests were carried to know the performance of SCC. And result obtained from the test ensured that this method give SCC of high quality as it is compared with other methods which were developed by Japanese Ready-Mixed Concrete Association (JRMCA) [1]. MANU SANTHANUM et.al has studied the properties of self-consolidating concrete and concluded that they will vary a lot from the regular slump concrete. They say concrete occupies the space in denser reinforcement and multiplexed composition elements. It will work under its unique weight and reasonably fill all pores without setting apart lavish bleeding, and air emigration, segregate of materials and not in need of vibration. Nowadays SC concreting is vastly used in every type of construction as it needs less labor, substance, and equipment [4]. P. SRINIVAS RAO et.al have worked on characteristic strength thirty, forty, fifty and sixty evaluate, FRSCC, conducted a demonstration to know the way of acting beneath flexion. Several researches conducted on GF in SC concreting blend. By using GF, chink gets bring down. Stance structure will go high about $0.03 \%$ than regular $0 \%$ adding.

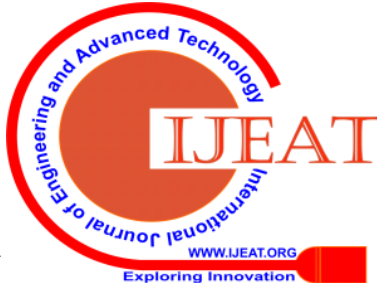
\& Sciences Publication 
Supplementation of Glass Fiber in SC concreting upgrades the flexion firmness. It will not upgrade the micro rift [6].

PANKAJ SHAH Et.al has studied that a regular concrete possess fine caliber and relativity of the concrete.

The deterioration present in the concrete predominantly due to tamping. To deal with this worry SC concreting is embraced. In this latest method state of concrete is enhanced, manpower risk will diminish, precise construction period, underneath construction price and vitally diminishes the uneasiness sound.

VINAYAK B JATALE et.al, a novelist made a research on brace oneself fibers in SC concreting joining the ash of fly, kaolin and flume of silica to book work on possessions of mechanical. SF reinforcement in SC concreting headway around poky RF, move beneath its mass and perfectly fill the blocks where supreme of this appraisal. In appraisal predominantly with affix of ash of fly, kaolin, flume of silica, PC deploys superplasticizer and SF. In SC concreting avail oneself of flattened SF and steel of ended hook fiber exhibit come down flexion robustness, set side by side to SC concreting [7].

K. NAGARAJU et.al has mentioned the inference that attain when they studied the response of self-compacting concrete. The SC concreting techniques didn't have precise blend designs. By utilizing traditional BIS blend techniques SC designs are done by modeling worthy reconstruction by the guidelines presuming by distinct firms. Have to do several try out procedures to keep inflow faculty, oneself affinity and snag clear out.

\section{MATERIALS AND ITS TESTING}

In this project, Chettinad 43 ordinary Portland grade was used with a specific gravity of 3.13 and a fineness of $4 \%$. Besides, Fly ash of genre $\mathrm{F}$ was used as a cement substitution for SCC blends with a specific gravity of 2.24. Glass fibers used to regulate the rupture which is precipitated by plastic shrinkage and drying in concrete. Superplasticizer was used for improving the workability of concrete mixtures. A Conplast SP430 is used with a specific gravity of 1.2 at $200^{\circ}$ $\mathrm{C}$ and Alkali content greater than 72 gram Na2O tantamount/ liters of admixtures. It has to be noted that aggregates are of different parts, namely the coarse and fine aggregate as well as the filler. Coarse aggregate with a maximum size of $12.5 \mathrm{~mm}$, a specific gravity of 2.68 and water absorption of $0.6 \%$ was used. The fine aggregate is river sand with a specific gravity of 2.59 and water absorption of $0.8 \%$. Portable water was used for the preparation of concrete mixtures.

\section{TRYOUT FOR SELF COMPACTION CONCRETE FRESH PROPERTIES}

- Ability to fill: concrete's aptness to drift beneath its mass both parallel and upright without honeycombing about all outlines.

- Resilience to setting apart: concrete's aptness to perpetuate a congruent blend during and after emplacement, without detachment of water from solids or aggregate from paste.

- Ability to pass: concrete's aptness to drift explicitly through condensed reinforcement without inhibits.
Table I: SC concrete tryout routine for properties of workability

\begin{tabular}{|c|c|}
\hline Routine & Property \\
\hline Flow of slump by Abrams cone & Ability to fill \\
\hline J-ring & Ability to pass \\
\hline $\mathrm{T}_{50 \mathrm{~cm}}$ flow of slump & Ability to fill \\
\hline Funnel of V & Ability to fill \\
\hline Funnel of V at $\mathrm{T}_{5 \min }$ & Setting apart resilience \\
\hline U-box & Ability to pass \\
\hline L-box & Ability to pass \\
\hline Fill-Box & Ability to pass \\
\hline Orimet tryout & Ability to fill \\
\hline
\end{tabular}

\section{MIX DESIGN METHODS FOR SCC}

\section{Trial mixes:}

After completion of the methodology blend design in the current appraisal, several try out blend designs were attempted to conclude for appropriate proportioning of the blend to mold the beams, cylinders, and cubes.

Table II: Try out blend proportions of SC concreting

\begin{tabular}{|l|l|l|l|l|l|l|l|}
\hline $\begin{array}{l}\text { Try } \\
\text { out } \\
\text { Blend } \\
\text { Id }\end{array}$ & $\begin{array}{l}\text { Cem } \\
\text { ent } \\
\mathbf{k g} / \\
\mathbf{m}^{3}\end{array}$ & $\begin{array}{l}\text { Ash } \\
\text { of } \\
\mathbf{f l y} \\
\mathbf{k g} / \\
\mathbf{m}^{\mathbf{3}}\end{array}$ & $\begin{array}{l}\text { Agg of } \\
\mathbf{c o a r s e} \\
\mathbf{~ k g} / \mathbf{m}^{3}\end{array}$ & $\begin{array}{l}\text { Agg of } \\
\text { fine } \\
\mathbf{k g} / \mathbf{m}^{3}\end{array}$ & $\begin{array}{l}\text { W/ } \\
\mathbf{P}\end{array}$ & $\begin{array}{l}\text { Wate } \\
\mathbf{r ~ l t r /} \\
\mathbf{m}^{3}\end{array}$ & $\begin{array}{l}\text { SP } \\
\mathbf{\%}\end{array}$ \\
\hline TM1 & 286 & 264 & 295 & 899 & 0.3 & 160 & 1.5 \\
\hline TM2 & 286 & 264 & 295 & 899 & 0.3 & 160 & 1.7 \\
\hline TM3 & 286 & 264 & 295 & 899 & 0.3 & 160 & 1.6 \\
\hline
\end{tabular}

Table III: Try out blends fresh properties

\begin{tabular}{|c|c|c|c|c|c|c|}
\hline \multirow{2}{*}{$\begin{array}{l}\text { Try out } \\
\text { blends }\end{array}$} & \multicolumn{2}{|c|}{ Slump Flow } & \multirow{2}{*}{$\begin{array}{l}\text { J-Ring } \\
\mathrm{mm}\end{array}$} & \multirow[t]{2}{*}{ U-Box } & \multicolumn{2}{|c|}{ V-Funnel } \\
\hline & $\begin{array}{l}\text { Dia } \\
\text { mm }\end{array}$ & $\begin{array}{l}\text { T50cm } \\
\text { sec }\end{array}$ & & & $\begin{array}{l}\text { T } \\
\text { sec }\end{array}$ & $\begin{array}{l}\text { T } \\
5 \mathrm{mi} \\
\mathrm{n}\end{array}$ \\
\hline TM1 & 656 & 6 & 10 & 25 & 10 & 2.8 \\
\hline TM2 & 700 & 4 & 5 & 7 & 8 & 1.8 \\
\hline TM3 & 685 & 5 & 7 & 15 & 11 & 2.4 \\
\hline
\end{tabular}

Blocks are molded coincide with these 3 try out blends for 7 and 28 days and perform the test. Try out Mix 2 is considered based on obtained results in fresh and hardened properties. 
Table- IV: Blend proportions

\begin{tabular}{|c|c|c|c|c|c|c|c|c|c|}
\hline Mix Id & $\begin{array}{c}\text { Aspect } \\
\text { ratio }\end{array}$ & Volume fraction & $\begin{array}{l}\text { Cement } \\
(\mathrm{kg} / \mathrm{m} 3)\end{array}$ & $\begin{array}{c}\text { Ash of fly } \\
\text { (kg/m3) }\end{array}$ & $\begin{array}{c}\text { C.A } \\
(\mathrm{kg} / \mathrm{m} 3)\end{array}$ & $\begin{array}{c}\text { F.A } \\
(\mathrm{kg} / \mathrm{m} 3)\end{array}$ & W/P & $\begin{array}{c}\text { Water } \\
\text { (ltr/m3) }\end{array}$ & SP (\%) \\
\hline Ag0Vg0 & 0 & 0 & 286 & 264 & 695 & 899 & 0.3 & 160 & 1.5 \\
\hline Ag1Vg1 & 875 & 0.25 & 286 & 264 & 695 & 899 & 0.3 & 160 & 1.5 \\
\hline Ag1Vg2 & 875 & 0.5 & 286 & 264 & 695 & 899 & 0.3 & 160 & 1.5 \\
\hline Ag1Vg3 & 875 & 0.75 & 286 & 264 & 695 & 899 & 0.3 & 160 & 1.5 \\
\hline Ag1Vg4 & 875 & 1 & 286 & 264 & 695 & 899 & 0.3 & 160 & 1.5 \\
\hline Ag2Vg1 & 1285 & 0.25 & 286 & 264 & 695 & 899 & 0.3 & 160 & 1.5 \\
\hline Ag2Vg2 & 1285 & 0.5 & 286 & 264 & 695 & 899 & 0.3 & 160 & 1.5 \\
\hline Ag2Vg3 & 1285 & 0.75 & 286 & 264 & 695 & 899 & 0.3 & 160 & 1.5 \\
\hline Ag2Vg4 & 1285 & 1 & 286 & 264 & 695 & 899 & 0.3 & 160 & 1.5 \\
\hline Ag3Vg1 & 1714 & 0.25 & 286 & 264 & 695 & 899 & 0.3 & 160 & 1.5 \\
\hline Ag3Vg2 & 1714 & 0.5 & 286 & 264 & 695 & 899 & 0.3 & 160 & 1.5 \\
\hline Ag3Vg3 & 1714 & 0.75 & 286 & 264 & 695 & 899 & 0.3 & 160 & 1.5 \\
\hline Ag3Vg4 & 1714 & 1 & 286 & 264 & 695 & 899 & 0.3 & 160 & 1.5 \\
\hline
\end{tabular}

\section{PREPARATION AND MOULDING OF TEST SPECIMEN}

In the occurrence of incorporating for SC concrete, at the outset, elementary aspects of concrete were incorporated in parched ambiance in the concrete blender for sixty seconds. Elementary aspects used for incorporating are cement, river sand, crushed gravel and fly ash. After that for acquiring unvaried blend, glass fibers were adjoined and incorporated thoroughly. To this parched blend, both to seventy percent of the gauged extent of water was spilled and incorporated detailed for sixty seconds. The residual thirty percent of water was incorporated with the superplasticizer and was adjoined into the blender and incorporated for 300 seconds.

To frame the cuboid prototype, a 150x150x150 millimeter frame of the cuboids was used. To make it easy to detach the prototypes, frames were lubricated before framing the prototypes. After 24 hrs frames were removed and the prototypes were preserved in curing tank. And relevant compressive sturdiness tryouts were carried out for 7 days and 28 days.

To frame the beam prototypes, a 500x100x100 millimeter frame of beam were used. To make it easy to detach the prototypes, frames were lubricated before framing the prototypes. After 24 hrs frames were removed and the prototypes were preserved in curing tank. And relevant flexural sturdiness tryouts were carried out for 7 days and 28 days.

To frame cylinder prototypes, frames of height 200 millimeter and 100 millimeter diameter were used. To make it easy to detach the prototypes, frames were lubricated before framing the prototypes. After $24 \mathrm{hrs}$ frames were removed and the prototypes were preserved in curing tank. And relevant split tensile sturdiness tryouts were carried out for 7 days and 28 days.

\section{RESULTS AND DISCUSSION}

Result obtained by the test conducted on fresh concrete

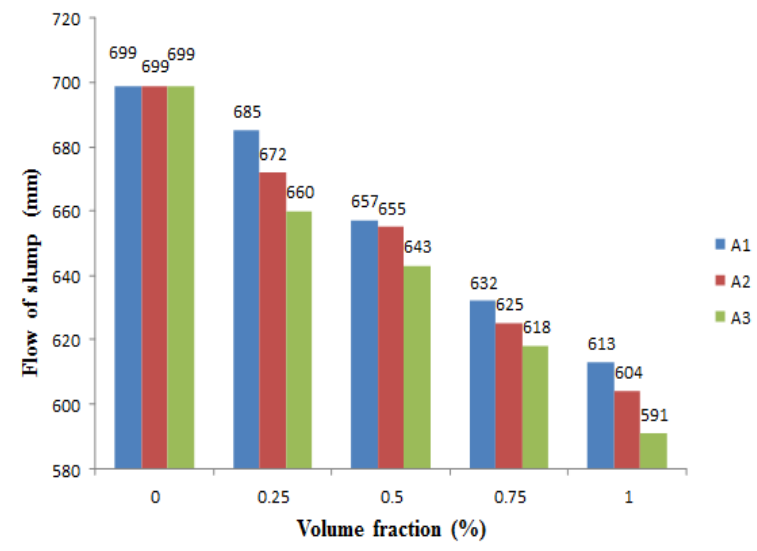

Fig 1: Flow of slump

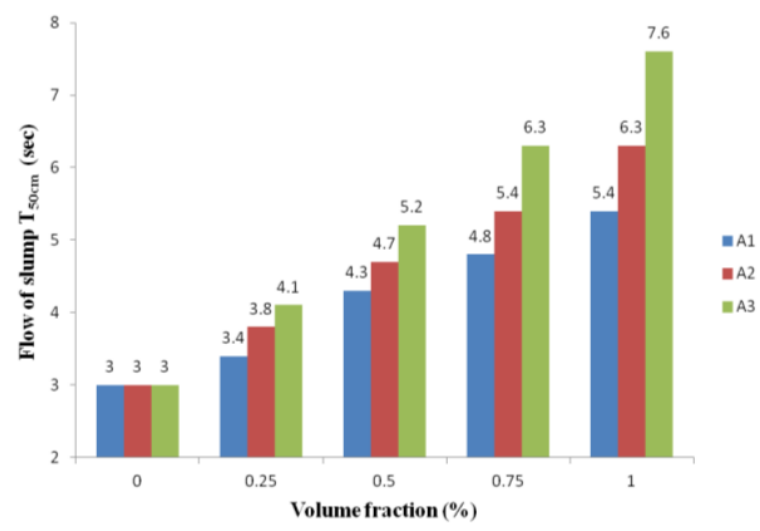

Fig 2: Flow of slump $T 50 \mathrm{~cm}$ 


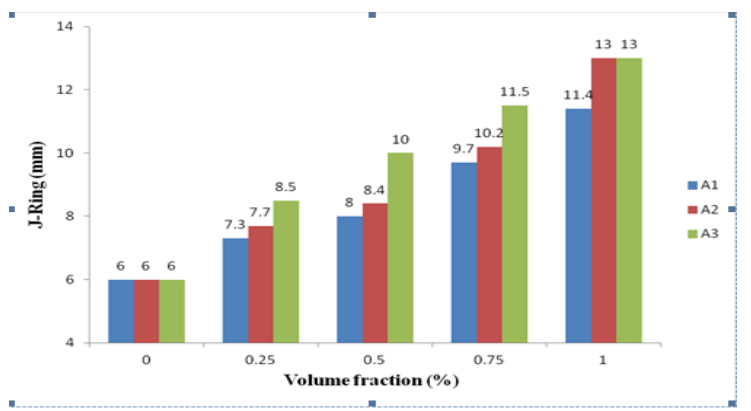

Fig 3: J-Ring

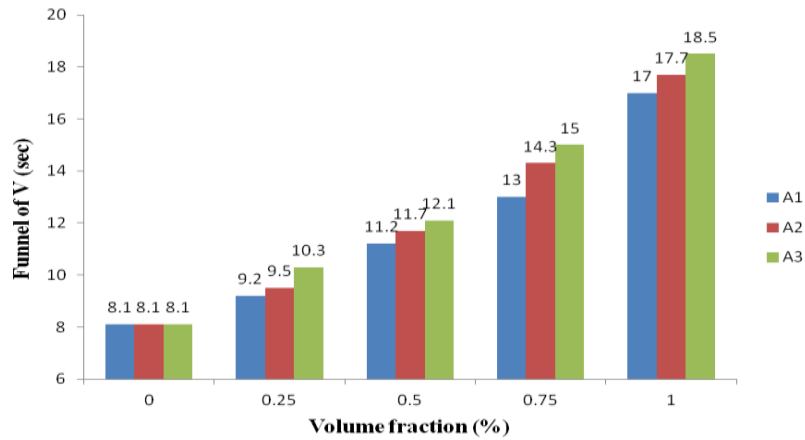

Fig 4: V-funnel

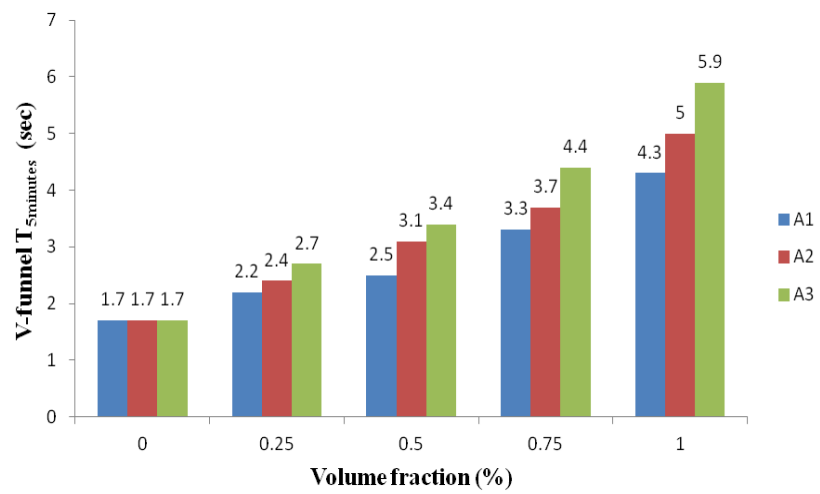

Fig 5: V-funnel T5min

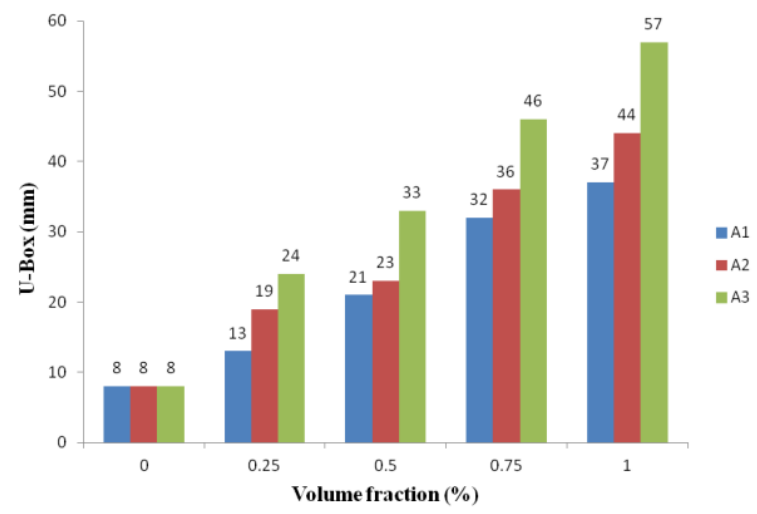

Fig 6: U-box

Results obtained by test conducted on hardened concrete

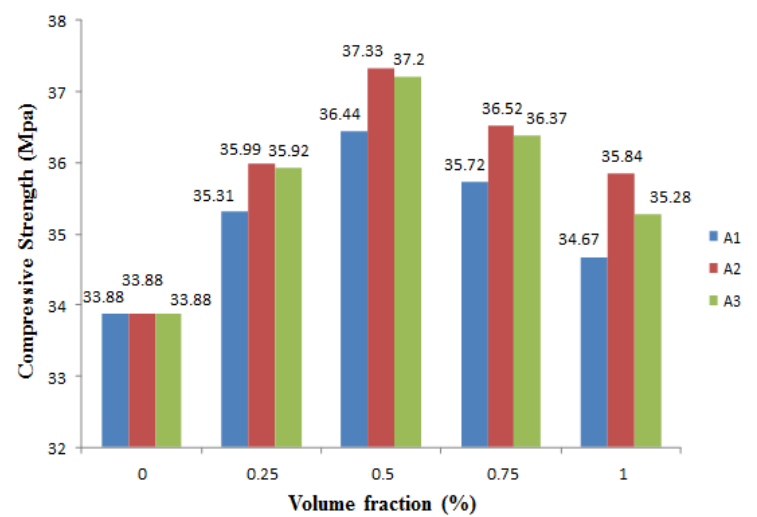

Fig 7: Compression Strength for 7 days

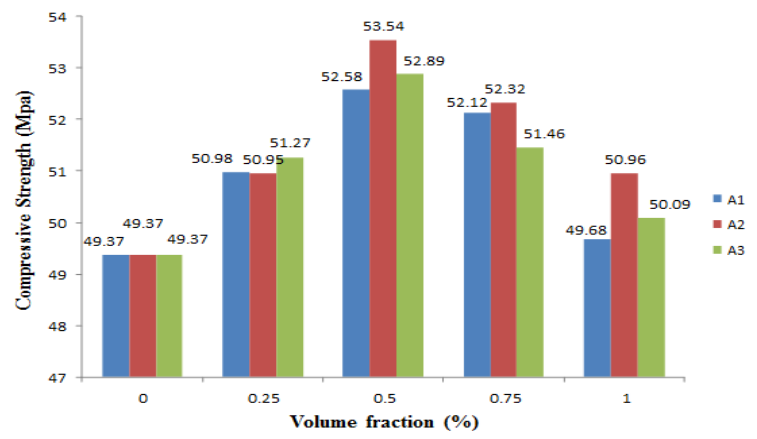

Fig 8: Compression Strength for 28 days

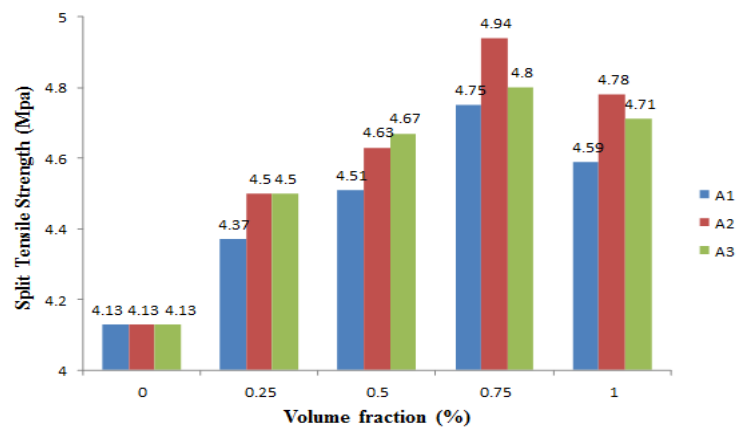

Fig 9: Split Tensile Strength for 7 day

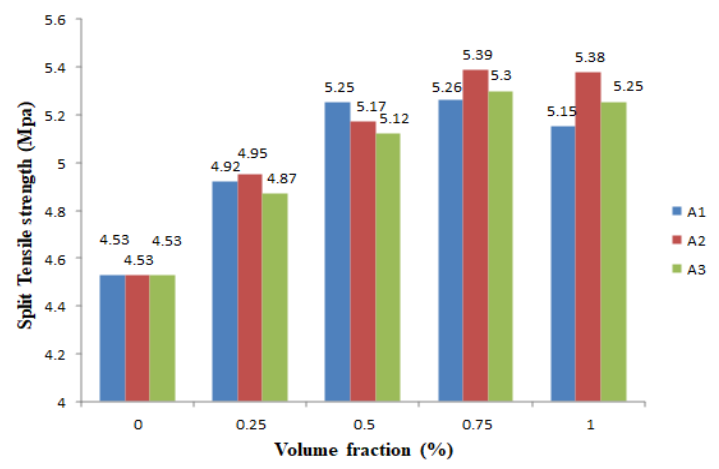

Fig 10: Split Tensile Strength for 28 days 


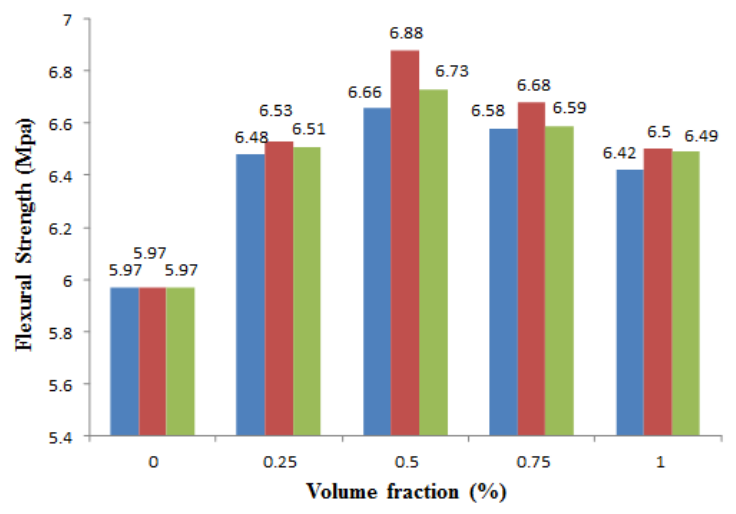

Fig 11: Flexural Strength for 7 days

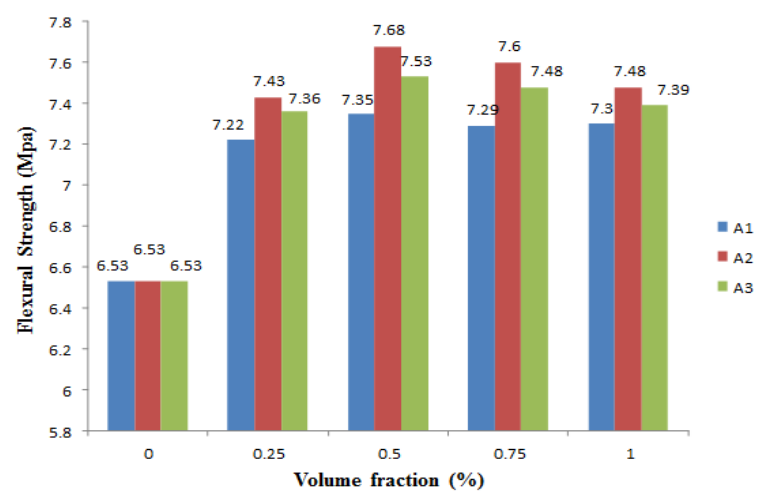

Fig 12: Flexural Strength for 28 days

By the results of hardened concrete tryout, we can perceive that the sturdiness of compression of all the blend compositions is in the scale of 33.88-37.33 for seven days and 49.37-53.54 for 28 days, the sturdiness of split tensile is in the scale of 4.13-4.94 for seven days and 4.53-5.39 for 28 days and the sturdiness of flexural is in the scale of 5.97-6.88 for seven days and 6.53-7.68 for twenty eight days.

By the result, we can see the proof that procure the glass fibers addition enhances the sturdiness as we obtain higher sturdiness in all the blend composition than Ag0Vg0 [control $\operatorname{mix}]$.

Contrast to all blends, mix Ag2Vg3 procure sizeable sturdiness of split tensile, this stipulates that the sturdiness of split tensile of SC concrete elevates up to aspect ratio 1285 and 0.75 of glass fibers volume fraction percentage. Also, contrast to all blends, mix Ag2Vg2 procure sizeable sturdiness of flexural and sturdiness of compression, this stipulates that sturdiness of flexural and sturdiness of compression of SC concrete elevates up to aspect ratio 1285 and 0.5 of glass fibers volume fraction percentage.

\section{CONCLUSION}

- The M40 genre SC concrete has satiated all the predominant attributes of ability to fill, ability to pass and resilience to segregation.

- The aptness to flow and aptness to pass of SC concrete diminishes as the aspect ratio and volume fraction of glass strands upsurges.

- By adjoin of glass strands; the brittleness of concrete is augmented. As concrete is immensely fragile in tension, the glass strands are valuable in axial tension to upsurge strength of tensile.

- Contrast to regular concrete, SC concrete gives adequate finishing lacking any superficial mean of compaction.

- We perceived that the utmost sturdiness of split tensile is procured when $0.75 \%$ of glass strands are adjoined contrast to $0.25 \%, 0.5 \%$ and $1 \%$ of glass strands.

- Contrast to adjoin of $0.25 \%, 0.75 \%$ and $1 \%$ of glass fibers, $0.5 \%$ adjoin of glass strands gain the utmost sturdiness of flexural and compression.

- Contrast to 875 and 1714 aspect ratio, utmost sturdiness of split tensile, sturdiness of flexural and sturdiness of compression is gained when glass strands of aspect ratio 1285 is adjoined.

- Preferable potential in respect of sturdiness of compression and sturdiness of flexural was found in $0.5 \%$ and in respect of sturdiness of split tensile was found in $0.75 \%$ of optimum volume fraction of fiber respectively.

- Preferable potential in respect of sturdiness of flexural, sturdiness of compression and sturdiness of split tensile was found in the 1285 aspect ratio of fiber.

- With the implement of glass strands, the development of numerous rupture and micro rupture are checked.

\section{REFERENCES}

1. Nan Su, Kung-Chung Hsu, His-Wen Chai, "A Simple Mix Design Method for Self-Compacting Concrete," Cement and Concrete Research 31, 2001, Pp 1799-1807.

2. Hajime Okamura and Masahiro Ouchi, "Self Compacting Concrete" Journal of Advanced C T, Vol. 1, No 1, 5-15 April 2003.

3. Timo Wustholz "Fresh Properties of Self Compacting Concrete", Ott-o-Graf Journal vol. 14, 2003.

4. Manu Santhanam et.al. "Investigation on Reactive Powder Concrete: A developing ultra-High-Strength Technology," The Indian Concrete Journal, 2004, 78(4), Pp 33-38.

5. Ganesan N, Indira P.V and Santhosh Kumar P.T, "Strength and Behavior of Steel Fibre Reinforced Self Compacting Concrete in Flexure", International conference on Advances in Concrete, Composites and Structures, held at SERC, Chennai, 6-8 January, 2005 Pp 475-484.

6. P Srinivas Rao, G K Vishwanadh, P Sravana and T Sheshadri Sekhar, "Flexural behavior of reinforced concrete beams using self-compacting concrete", 34th Conference on Our World in Concrete and Structures: 16-18 August 2009, Singapore.

7. Vinayak B. Jatale and M. N. Mangulkar, "Flexural Behavior of Self Compacting High Strength Fiber Reinforced Concrete", International Journal of Engineering Research and Applications Vol. 3, Issue 4 Jul-Aug 2013, Pp. 2503-2505.

\section{AUTHORS PROFILE}

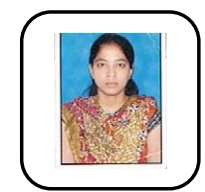

Harshitha M N, Assistant Professor, Department of Civil Engineering, JSS Academy of Technical Education, Bengaluru, India

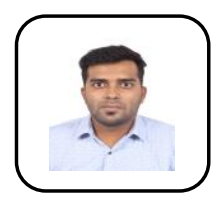

Nikhil Khatavakar, Student, Department of Civil Engineering, JSS Academy of Technical Education, Bengaluru, India 